\title{
POLISH MIGRATION'S SOCIO-CULTURAL IMPACT ON WALES IN THE AFTERMATH OF 2004 - PRELIMINARY FINDINGS FROM WESTERN WALES:AN ABERYSTWYTH CASE STUDY
}

\author{
PAWEŁ WRÓBEL
}

Aberystwyth University

\begin{abstract}
This papers looks at the societal and cultural impact of the post-2004 Polish migration to Wales. The history of Polish migration to the UK is introduced together with the relevant statistics and their rationale behind choosing cosmopolitan Wales as their new country of residence. Even though the focus of the paper is rather on the UK as a whole, it is Wales that is central to the investigation. Wales was particularly neglected in the study of migration in the aftermath of the 2004 European Union (EU) enlargement and surprisingly little attention was given to it. Focusing on Polish diaspora is important as it is the most numerous external migration wave to Wales (ONS 2011). The case study of Aberystwyth is introduced as a good example of a semi-urban area to which Poles migrated after 2004. Moreover, the paper elaborates on the characteristics of the Polish newcomers by analysing their distinctive features, migration patterns as well as adaptation processes. Mutual relations between post-1945 and post-2004 immigration waves are investigated, together with Poles' own image and perception. This paper gives a deeper understanding and provides an insight into the nature of the Polish migrants' impact on the cultural and societal life of Wales.
\end{abstract}

Keywords: Wales, Poland, migration, 2004, socio-cultural 


\section{Introduction}

In 2004 the fifth enlargement of the European Union (EU) took place. That expansion made it possible for Poland and nine other states to become a part of a larger community with common values, open borders and an interconnected economy. The United Kingdom (UK) during this period experienced the largest wave of immigration in its history (Drinkwater and Garapich 2011). In total, over 1.2 million people migrated to the UK between May 2004 and April 2011, with the vast majority coming from Poland -1 around 66\%, i.e. 800,000 of immigrants to the UK (Longhi and Rokicka 2012). The UK was one of only three other EU member states, apart from Sweden and the Republic of Ireland that decided not to impose any restrictions on migrants who could freely start to work in Britain after 1 May 2004. However, the UK was in general mainly lacking people who would be interested in undertaking the so- called 'simple jobs' and effectively work for the minimum wage. This was seen as a great chance to attract the attention of people from Central and Eastern European states whose economy was not prospering that well and, what is more, was often underperforming at that time.

Certainly, specific socio-economic phenomena such as the outbreak of the 2008 economic crisis had an impact on the migration patterns as well as the future domiciles chosen by the newcomers, even though statistically, the influx of migrants had slowed down by that time (Findlay and McCollum 2011). One of such destinations which became increasingly popular towards Polish migrants was Wales. Polish newcomers were more likely to migrate short-term and temporarily to Wales and many of them had a fairly clear plan to stay there for a relatively short period of time (Drinkwater and Garapich 2013). Despite residents born in Poland constituting the most numerous non-UK born group in Wales, which in 2011 was according to official statistics 18,023 people (Migration Observatory 2014), over ten years after Poland's accession to the EU relatively little attention has been paid to the socio-cultural impact that Polish migration has had on Wales.

Researching contemporary European diasporas in Wales is significant for a number of reasons. It is a minority nation with a rich postcolonial migration tradition in which people coming from different cultures meet on a daily basis. The vast majority of literature available focuses on migration movements to urban areas located predominantly in Southern Wales, most often Cardiff, particularly among residents from Britain's former colonies. Little attention has been paid to the most recent migration waves, especially to the rural areas located outside of South Wales. This article, based on my doctoral research, will fill the gap in knowledge in this area of research by shedding light on Polish migrants' experiences in Aberystwyth with respect to the socio-cultural impact 
in a bilingual context. The local character of rural Wales will be discussed as well as its cosmopolitanism that should not be limited to South Wales. However, in order to understand certain socio-cultural mechanisms, changing dynamics as well as actions, it is important to survey the history of Polish migration to the UK with a Welsh focus in a much more detailed way.

\section{History of Polish migration to the UK}

The history of Polish migration to the UK is broad and diverse. The composition of different Polish diasporic groups consists of post-Second World War combatants, their wives, Polish Jews, but also members of the Solidarity who had to seek exile until 1989 (Drinkwater and Garapich 2011). According to the 1951 Census, the Polish-born population in the UK at that time was over 162,000 (Sword 1996). It is very important to bear in mind that between 1960 and 1990 there was a significantly small pattern of migration between Poland and Great Britain, compared with the one after the Second World War or after the 2004 EU enlargement, which effectively resulted in a substantial elderly Polish population by 2001. It was definitely caused by the political situation in Poland, Moscow's significant influence as well as serious difficulties when one wanted to migrate from Warsaw to elsewhere.

This noticeable disproportion in terms of age had a substantial impact on the relations and mutual perception of those two major immigration groups, i.e. those who settled over 50 years ago as well as the newcomers who recently decided to migrate and seek a better life in Wales, among other places. I agree with Drinkwater and Garapich (2013), who claim that a symptomatic demographic change in the aftermath of the 2004 EU expansion had a significant impact on the development of the literature regarding that wave of migration to the UK. However, there is a very little data regarding migration to Wales in the $20^{\text {th }}$ century specifically, as the only available censuses conducted by the UK Government are from 2001 and 2011 (Stat Wales 2016). For the purpose of this study, the latter census is employed. Hence, it is rather difficult to provide a comprehensive analysis of the pre2004 Polish migration to Wales that would holistically break down the presence of Polish nationals periodically.

Nonetheless, the majority of the most recent Polish migrants to the UK decided to leave their homeland for purely economic reasons and free access to the labour market was undoubtedly a crucial variable which had a great impact on their choice. The openness as well as the generosity of employment opportunities in Britain were instrumental when citizens of Poland who were motivated to migrate elsewhere started to think thoroughly about their future 
country of residence. Many of these jobs were not necessarily considered very favourably initially by the native population or undertaken long-term because of their very nature or the relatively low wages. When one compares, at that time 12 years ago, the minimum wage or the hourly wage with the one offered in Poland, it was at least four or five times higher (British Government 2016). Many of those who left their homes were working under their qualification level, but one of the common denominators amongst them was the goal to save some money, to be able to send the remittances back to Poland or, simply, be able to have an affordable, independent life in the UK. Regardless of the particularities of individual stories, members of the post-2004 Polish migration to the UK, were in one way or another driven mostly by economic factors.

Moreover, Poles were very eager to consolidate their knowledge and learn about British laws and various aspects of the legislative system in order to know their rights and obligations, but also so that they could feel more confident in their new reality. Therefore, quite often their fluent adaptation into the British environment is a result of their awareness and self-consciousness regarding their agenda, long-term plan, mobility and readiness for assimilation or in some cases, an ability to just leave their former life back in Poland. The vast majority of my interviewees openly admitted that they do not experience longing for Poland or their relatives, because of a psychological and physical sense of proximity, both technological and geographical. Furthermore, many of them are capable of creating a microcosm in the UK and are no longer fearful of losing their Polish identity, which was seen as a consequence of the tragic events which occurred between 1772 and 1989 (Rydzewska 2012).

\section{Poland as a country of emigration}

From a historical perspective, Poland could be considered as a country of emigration due to the eighteenth-century partitions of Poland, the First and Second World Wars, but also because of direct Soviet influence from 1945 to 1989. Poland was continuously disappearing, reappearing and shifting significantly back and forth on European maps. Hence, one could notice that due to external factors (that were not caused by Poles themselves), the mobility of Polish citizens was rather something obvious, unconstrained, and considered natural as many were simply fleeing their homeland because of aggression. Poles were highly motivated to leave their home country during very difficult periods when the political climate, economic situation as well as such matters as freedom of speech, press or thought were problematic. Although it could be easily understood why Poles were that determined to 
leave Warsaw between 1945 and 1989, it could have been surprising for many why they decided to move again after 2004, when their country had just started a new, fresh chapter in their history and was on a better path of development, modernity and progress.

Norman Davies argues that "for the Poles, the West is a dream, a land beyond the rainbow, the lost paradise. The Poles are more Western in their outlook than the inhabitants of most Western countries" (Davies 2001: 303). Undoubtedly, historical events in the last 300 years have not only shaped to some extent a Polish identity as such, but also contributed effectively to the geographical dispersion of various diasporic group in Europe and on other continents. Because of this proximity, Polish people started to migrate to such countries as the UK, Germany, Sweden or Norway where the social care and benefits system are better developed and more generous than the Polish one. The omnipresence and rapid expansion and growth of budget airlines such as RyanAir, WizzAir or EasyJet contributed to the numbers of Poles who started flying to the UK, as well as the number of airports both in Poland and in Britain which began to offer various multiple flight connections - to date RyanAir has 44 air routes, WizzAir 23 and EasyJet only one which gives in total 68 connections (last checked 28 January 2016). Although there are no direct flight connections offered by budget airlines between Poland and Wales, the proximity of airports located in Liverpool, Manchester, Birmingham or Bristol facilitate the movement between these two countries. Moreover, it is fairly easy to commute to Wales by train in general, and the development of various bus services as well as the introduction of new routes, most prominently by Megabus, a long distance coach operator, make it possible to travel across Wales swiftly. The aforementioned socio-economic factors, Poles' mobility as well as rapid development of technology and transportation services, triggered the post-2004 migration not only to the UK in general, but also to Wales in particular.

\section{Cosmopolitanism in Wales}

Wales with a population of over 3 million should be regarded as a cosmopolitan state. Although around $20 \%$ of its inhabitants speak Welsh, a correlation between the language and Welsh identity is very often contested (Scourfield and Davies 2005). Between 2001 and 2011, the foreign-born population in that country increased by $82 \%$ and constituted $5.5 \%$ of the total Welsh population (Office for National Statistics 2011a). The phenomenon of multiculturalism is particularly (but not exclusively) visible in South Wales, especially in places like Cardiff, Swansea or Newport. The non-UK born population in the capital of 
and largest city in Wales doubled between 2001 and 2011, and accounted for $13 \%$ of all residents (Office for National Statistics 2011a) which some use to describe it as a 'super-diverse' city (Threadgold 2007: 5). At the same time, Newport had the second highest population share of non-UK born people $(8.5 \%)$ and Swansea was home to 17,233 non-UK born residents, which was the second highest number in Wales. Certainly, these figures are to some extent a reflection of the postcolonial migration to Wales which started at the beginning of the 1950s. Although migrants came to the major metropolitan areas of Britain, the port city of Cardiff was also popular among them (Bosma, Lucassen and Oostindie 2012). At the same time, I agree with Bohata (2004) that Wales is often missed out entirely of the postcolonial discourse due to an Anglo-centric culture, as well as its proximity to England.

Nonetheless, although one could observe the dominance of South Wales with regards to ethnic diversity, it is necessary to turn from urban to rural focus and investigate cosmopolitanism in other areas. The specific place that will be investigated in this paper is Aberystwyth. The university town located on the western coast of Wales is a place where both Welsh nationalism and multiculturalism are visible (Jones and Fowler 2008). The existence of national institutions such as the Aberystwyth University and the National Library of Wales, which were the products of a nineteenth-century cultural revival, could be regarded as strong symbols which bring these two phenomena together (O'Leary 2015). A relatively small town has multiple networks that are responsible for different socio-cultural impacts such as the existence of societies, establishment of businesses or organisation of events. Therefore, cosmopolitanism is both a historical legacy that was often associated with postcolonialism and often limited to South Wales, as well as a reality for other locations in Wales, particularly in the aftermath of $2004 \mathrm{EU}$ enlargement.

\section{Post-2004 Polish migration to Wales}

In order to understand certain similar characteristics of Polish migrants who decided to migrate to Wales, it is absolutely essential to be familiar with the term 'migration industry' that contributes to the study of Polish migration to the UK in general and Wales in particular. Garapich, who is the author responsible for coining that notion, claims that "migration industry should be understood as a particular sector of the service economy that stimulates mobility and eases adaptation" (Garapich 2008: 735). It is very important to break that definition down as it includes three key words that ultimately characterise Polish migration after 2004 - these are: 'economy', 'mobility' and 'adaptation'. All 
three are interconnected in a very specific way that collectively determines the future of particular migrants when it comes to long- and short-term decisionmaking regarding their very living, geographical trajectories with respect to their domicile as well as their assimilation or separation within or from a given society and which ultimately decides on their integration (or not).

Thompson, Chambers and Dołeczek agree that Wales was and still is particularly neglected with respect to the research on A $8^{1}$ migration, and Polish migration in particular (Thompson, Chambers and Dołeczek 2010). The main rationale behind this extensive migration was the weak and underperforming Polish economy four years before the start of the economic crisis when the unemployment rate was 19\% amongst Polish citizens (Ministerstwo Pracy i Polityki Społecznej 2008). Currently, those remaining jobless in Poland consisted of around $9.6 \%$ which is regarded by the current government of Prawo i Sprawiedliwość (PiS) under Prime Minister Beata Szydło, as a big challenge and a significant problem (Główny Urząd Statystyczny 2015). Moreover, specific demographic conditions in Poland, an observable recession in the UK labour market and the strengthening value of the Polish złoty to the pound sterling back in 2004, also encouraged Poles to migrate. What is more, recent migrants from Poland, similarly to other A8 states, were more geographically dispersed across all of the UK territory. Initially, Poles migrated to large cities or conurbations such as London, Liverpool, Manchester, Birmingham, Glasgow, Edinburgh, etc. The trend started to gradually shift in 2008 due to the outbreak of the economic crisis and the first stage of the job market saturation. From that moment onwards not only were the rural parts of the UK more often chosen by the new migrants as their future domicile, but also former migrants started to change their places of residence. Therefore, the phenomenon of the 'escalator migration' started to become visible amongst Polish newcomers who were predominantly interested in improving their socioeconomic status. In order to achieve that, they often chosen new 'escalator regions' which met Fielding's formal conditions, i.e. attractiveness of a region, social mobility of the locals and in-migrants and a significant proportion of outmigrants (Fielding 1992).

According to the 2011 Census for Wales, 18,023 Polish-born residents represent the most numerous external diaspora in Wales which translates into $11 \%$ of the total non-UK born population in that country (Office for National

The A8 countries are a group of eight of the 10 countries that joined the European Union during its 2004 enlargement. They are commonly grouped together separately from the other two states that joined in 2004, Cyprus and Malta, because of their relatively lower per capita income levels in comparison to the EU average (http://news.bbc.co.uk/ 2/hi/programmes/panorama/4479759.stm, accessed 2 June 2016). 
Statistics 2011a). In contrast to 2001 when there were 1,427 Polish-born people in Wales, there has been a significant growth of $1.163 \%$. The largest migrations of people from Poland were observed in places such as Cardiff, Wrexham, and Llanelli, although it is worth noting the unique location of Llanybydder. That market town with a population of 1,638 is home to over 200 Polish newcomers (Office for National Statistics 2011b, Kreft and Ritchie 2009). The vast majority of them are employed in Dunbia Meat Processing company. Around 3\% of the total post-2004 Polish migration decided to choose Wales as their place of residence which corresponds with Wales' 5\% share of the total UK population. (Drinkwater and Garapich 2011, Office for National Statistics 2011b). The Welsh capital, Cardiff, serves as a great hub that attracts many migrants and has a historical record of multiculturalism. In the case of Wrexham, an industrial city located in north-east Wales, very close to England, the vast majority of the Polish immigrants were attracted by the actual numbers of job vacancies in the cleaning, production and other services branches that were not necessarily those desired by the indigenous and local inhabitants. Finally, the example of Llanelli is peculiar since its popularity among Poles was a result of the activity of a company that was mainly responsible for the recruitment of workers. This job agency located in a relatively small Polish town helped many individuals who were eager to leave their homeland, leave Warsaw and start living in a previously unknown Wales. Although both the English and Welsh media regard this town with a population of 40,000 as a hotspot for the members of the Polish diaspora, and continuously say that there are around 10,000 Poles in Llanelli and the Gwendraeth Valley, the more accurate, however not confirmed and therefore elusive, number of Polishborn persons is 2,000-2,500 (Thompson et al. 2010).

With regard to specific data about the most recent Polish migration wave, it shows that it was slightly male-dominated (56.2\%) and relatively young, as over 80.9\% were aged between 16 and 34 years old (Drinkwater and Garapich 2011: 7). That is why one could assume that the age factor could play a significant role when determining the length of stay in the UK. Post-2004 migration has been significantly short-term and has had a more circular nature (Drinkwater and Garapich 2011). Longhi and Rokicka list other common characteristics of a Polish migrant to the UK after 2004. They claim that 'a typical migrant' or the one with the most frequent profile would be married, with children, not living in London, earning rather lower wages, seeking paid, full-time employment, with the intention to stay for a rather shorter than longer period of time in one place, and not being interested in investing in human capital such as learning the English language or developing hard competences and skills (Longhi and Rokicka 2012). It is also possible to observe that the vast majority of Poles worked in the following six sectors: manufacturing, financial services, construction, transport, public sector and hospitality (Longhi and Rokicka 
2012). Moreover, the employment rate after 2004 has been around $84.6 \%$ amongst Poles in the UK in general (Office for National Statistics 2011c). Polish migrants to the UK had the highest employment rate of any nationality, including the British citizens. They have mainly found jobs in semi-routine or routine occupation where they were paid relatively low wages (Drinkwater and Garapich 2011). A typical post-2004 migration destination was represented by a British city, whereas after 2008, Poles have started to migrate to rural areas or smaller towns as well. However, regardless of the location chosen, Polish migrants display quite similar features related to their motivation behind decision on migration, mobility or age.

\section{Mobility}

Such a numerous migration to Wales would not have been possible if Polish citizens were not mobile. It is worth noting that although a little more than a decade is not a significant period of time as such, the technological progress that was made by the whole world in general during the last 12 years has nevertheless been significant. Hence, we should certainly consider mobility to be a feature that does allow individuals unconstrained freedom of movement in a purely geographical or spatial sense, but at the same time it is important to highlight the value of its other forms. One such kind would be the electronic one that makes it possible to be in touch with the rest of the world because of the presence of telecommunications represented by mobile devices such as smart phones, smart watches, tablets or laptops, all of which can now be swiftly connected to the Internet in almost every single place worldwide. Therefore, one could argue here that it is to some extent much easier to become or simply be mobile nowadays than it was in 2004.

Still, Fomina and Frelak (2011) mention Poles' ability to go outside of their own environment, openness to the establishing of new relationships that are independent of any class, religious or ethnic divisions and the existence of civil society represented by membership in clubs, organisations or societies, etc. Undoubtedly, mobility could be reinforced by the individual approach to others and attitude towards 'the unknown', but at the same time one should remember about the very structure of the Polish society and those similar to it if someone is interested in extrapolating this example by using it as a case study. Arguably, such a mono-ethnic and fairly homogenous society as the Polish one is dominated by Christians in general and Catholics in particular and has a relatively insignificant influx of migrants, and in particular those coming from a different ethnic or religious background, could be a barrier. This obstacle could be quite challenging to overcome when one finds himself or herself in a 
completely unfamiliar socio-political climate where multiculturalism has been established for many years. Yet, integration of the Polish post-2004 migrant has been rather positively perceived by the British which is partly related to the phenomena of generosity, kindness and hospitality which is one of three major theoretical concepts of my Ph.D. work.

\section{Migration patterns}

Another very common argument explaining such a large Polish migration to the UK was the relative proximity of Poland and Great Britain. Longhi and Rokicka made the argument that nowadays it is much easier to travel because of the existence of the aforementioned cheap airlines such as RyanAir, EasyJet or WizzAir (Longhi and Rokicka 2012). Although the choices are many, not only those of budget flight operators but also others, it was noted by some respondents that often visits and longing for Poland could make the adaptation process more problematic.

Wider migration patterns regarding the Polish diaspora in Wales could be considered as unpredictable, liquid or even undetermined (Drinkwater and Garapich, 2013). Quite often, financial aspects play an essential role with regard to particular migration plans. The power of money and work in that respect is great and has a significant impact on possible changes in future plans for migration (Drinkwater and Garapich, 2013). Vertovec (2009) coined the term 'transnational type consciousness', which probably is very close in mirroring the very image and self-perception of Polish migrants who try to balance between their homeland and migration domicile. Being in limbo between their home town in Poland and their current domicile somewhere in Wales could certainly be well handled by some individuals who have no problem with finding a balance in their life, however many have two lives, and a bridged identity, resulting from their physical presence in Britain and their psychological presence in Poland.

\section{Post-1945 and post-2004 diasporas mutual relations}

In contrast to other migrants coming, for instance, from Italy or the Republic of Ireland, Poles who decided to go abroad in search of a better life are not necessarily interested or strongly motivated to seek out their compatriots in order to establish some significant relations. The post-2004 diasporic wave does not expect any support from the post-1945 one since it is not only focused on maximising their migration experience on different levels, one of which is the ability to be able to operate in a new environment independently with no or 
limited assistance (not necessarily offered by fellow Polish migrants, especially the elderly). What is more, there is a high level of mutual mistrust amongst these fellow-ethnicities who collectively contributed to the actual collapse of a sense of a Polish community as such (Garapich 2008). The former, older migrants do not have the best opinion about the younger, post-2004 migration and, hence, these two groups have a rather cool or even a poor relationship. In fact, according to Thompson et al. (2010), we cannot talk about the Polish 'community' at all.

Although a certain level of negativity is present, individuals are often discouraged from starting new relations and live their lives separately from the Polish minority in this or that location. A lack of solidarity among different Poles in the UK might be surprising to some because of the difficult history and some tragic events from the past, but the sad truth, often mentioned by my interviewees, is that in general Polish people are mostly able to (re)unite with other compatriots in very specific situations where their life is in danger or if something terrible for the whole nation has happened. According to Fomina and Frelak (2011), there is an ongoing rivalry among Polish fellow migrants who are interested in comparing almost every single aspect of their lives such as: individual successes, jobs which they currently do, wages that they currently earn, home standards, possessed cars and even English language skills and knowledge. These factors together with envy and jealousy cause tension and mutual anxiety which contribute to the lack of trust that then occurs. Not only was it a lack of unity that made it difficult to establish any decent relationships within the entire Polish community in the UK, but also the members' of the post-1945 migration bad opinion about the fresh migration wave. Those who had started from scratch six decades before them claimed that the newcomers had a demanding attitude towards life which is just inappropriate and disrespectful (Fomina and Frelak 2011). Therefore, the older group or their descendants are surely reluctant to create or establish any deep or significant relations with the post-2004 diaspora. It is because the former perceive the latter as a cohort that is not able to appreciate all the possibilities available in the UK, has little respect for their new environment or place of residence, but also because they seem to think that the younger group is simply continuously taking everything for granted. Hence, one could surely argue that, even though Poland and Polish people have a rich tradition or history of migration to the UK, various groups that have migrated in different periods of time are unwilling to stay in good relations, support each other and preserve Polish history, culture and legacy abroad collectively.

Sadly, individual attempts are made, but often it happens that they occur at the same time when it could have been a united and syngerically developed effort. Garapich claims that the Polish diasporic sphere in the UK was largely dominated by the more elderly community that was established or simply originated from the post Second World War migration (Garapich 2008). This is 
particularly important as the post-2004 migrants have experienced problems caused by different institutions that were responsible for the promotion of Polish culture, history and tradition which were almost inaccessible for recent newcomers. Hence, one could regard that the existing status quo was hard to overcome if one wanted to become an active member or activist of certain organisations and that is why new organisations have been set up that were completely separate from the ones run by the senior clique.

\section{Poles' own image and perception}

The most popular stereotypical image of a Polish migrant in the UK consists of three important factors - these are: being hard-working, having a Catholic work ethic and expressing relative cultural proximity. Hence, one could assume that the image of Polish migrants in the British society was and still is largely positive because of many similarities. Poles are perfectly aware of their identity and do not have serious problems in establishing, preserving or just manifesting it while being in the UK (Fomina and Frelak 2011). Fomina and Frelak's findings have been confirmed by my interviewees who, by indirect acclamation, agreed that they have no problems with who they are or what identity they actually possess. The vast majority of them are open and very happy to establish new contacts or relationships with the British community and have a relatively high self-esteem.

Poles are to a lesser extent interested in establishing relations with other Poles as noted before and, therefore, solidarity amongst Polish migration in the UK so-called 'Polonia' is not that apparent or popular (Fomina and Frelak 2011: 26). Intergenerational rapport is rather poor and has many flaws and that is why the groups are more often than not separated from each other, and despite the fact that rare, incidental events do occur where these two meet. The younger diasporic wave is not that strongly connected to their homeland in the patriotic sense or longing for it. British newspapers generally described Poles as easy, fast learners who are keen on integration and who know their own value (Fomina and Frelak 2011); however, the tabloids in particular also depicted negative features, saying that some Poles are prevaricators, racists, alcoholics, drunks, abusers of the benefit systems and failures (Fomina and Frelak 2011). However, a generally positive image comes from the more respected, 'reliable' or widely recognised newspapers with a better profile, tabloids depicted Poles as mostly hard-working individuals. This is very important from a psychological point of view, since the majority of human beings' internal or own perceptions depends highly on how they are actually perceived by others (Fomina and Frelak 2011). That could play a highly significant role when it 
comes to adaptation process, investment and the development of human capital or even decision as to stay in the UK longer or not.

To conclude, Polish migrants have not decided to come to the UK in order to stick together as a group in a foreign country. The very fact that Polish migration constituted such a large diasporic wave in the aftermath of Warsaw accession to the EU in 2004 was not an essential factor where the migrants were making decisions on choosing the UK as their future domicile. Although so many people decided to move to different parts of Britain, the established networks of Polish compatriots did not make any significant difference that was responsible for attracting their attention so that they could choose coming to the UK. Certainly economic motivation as well as mobility of Poles has a very profound impact on their integration ability. At the same time, the presence of various family members, relatives or even friends could undoubtedly reinforce the adaptation but it does not appear to be the key variable or an indispensable condition that has to be fulfilled in order to allow Poles to integrate into multicultural, British society. "Poland is in Poland and we do not feel any longing (for it)" said one respondent in Fomina and Frelak's study (Fomina and Frelak 2011: 22). However, the proximity of their homeland due to the existence of Polish shops, the Catholic Church, cheap flights offered by budget airlines, media, schools, offices, solicitors, doctors, food, customs, and people is perceived as something important. The Polish diaspora in the UK should be considered as highly diverse not only because of the outstanding numbers when it comes to the population, but there are many common denominators regarding their expectations, motivation or situation.

\section{Methodology}

After providing and sketching the broad context of Polish migration to the UK with respect to the history of migration to the UK in general and to Wales in particular, individual characteristics, relations between the most numerous diasporic waves as well as self-perception, let me focus now on the study conducted in West Wales, namely in Aberystwyth in spring of 2014. The study has been conducted as an integral part of my $\mathrm{PhD}$ research in this university town located by the Cardigan Bay, with eight people - four males and four females - who were between 23 to 52 years old; they came from different parts of Poland and were students or professionals who migrated to Wales for different reasons after Polish accession to the EU in 2004. The socio-economic profile of the sample is varied. Some of the participants were directly responsible for organising events that were promoting Poland, some were employed in the commercial sector which involved selling Polish goods and 
some belonged to different societies which brought Polish people together. Some of them were recruited through the usage of social media via snowball sampling method; some were found and agreed to be interviewed after visiting two particular sites: a Polish shop in Aberystwyth, and the Aberystwyth University's Penglais Campus. The average time for an interview was 24 minutes and these interviews were conducted in both of the above mentioned sites of recruitment as well as in my own office. For the purposes of this paper I focus on those aspects relating to the socio-cultural impact and integration only, these are:

What is it like to be a member of the Polish community in Wales? Do you feel integrated? Please explain your opinion.

AND

How does the Polish diaspora express its own cultural legacy in Wales? What are your experiences related to that? (What does "diaspora" mean to you?)

\section{The Polish community in Aberystwyth}

The majority of interviewees stressed the fact that in Wales there is a significant Polish community. Polish families who live in Wales are interested in staying in touch with their relatives in Poland, but because of the Poles who are also present in Wales, they feel comfortable and safe. Furthermore, being a member of the Polish community could be a difficult task because of the cultural differences and can ultimately depend from first experiences of a migrant:

\footnotetext{
When I first came here I was living in a flat with Britons only, and it was a serious challenge to integrate. After a while everything got better, but in the beginning it was very, very difficult (interview with Respondent 1).
}

At the same time, these individuals who felt well treated and welcomed could have potentially taken further steps in order to blend or integrate with the community such as applying for the British citizenship after meeting all the eligibility criteria. However, even though Poles in Aberystwyth have extensive representation comparing to the official number of citizens according to 2011 Census - 13,040 (Office for National Statistics 2011d) which is around 500 and the majority of people know each other, not every single individual necessarily feels well integrated with his or her fellow compatriots. By staying more open to other cultures, the perception of the many aspects of living related to integration with other Poles abroad may change. Polish people try to meet other families when celebrating birthdays or significant religious holidays such as Christmas or Easter. According to one interviewee a typical Polish family in 
Aberystwyth looks as follows:

\begin{abstract}
The husband is working, the wife is working, and later she takes maternity leave, and that is how... it normally functions without thinking about whether I will be able to afford buying this milk or something. They start families, live together somewhere... not in the centre (...) the second time a wife or a girlfriend gets pregnant, it is harder to come back to work, but... the majority think about starting a family and surely do work (interview with Respondent 2).
\end{abstract}

At the same time, one respondent who is still a student openly admitted that some Polish people may be responsible for the reproduction of negative opinions or rather a poor reputation, and create a situation whereby a Pole is no longer so proud of coming from Poland. That respondent said that immigrants, regardless of their nationality, should respect the Welsh and English languages, and stop using their first language in the presence of Welsh or English people. At the same time, some of my interviewees openly confess that they have no contact with their compatriots whatsoever because of their low level of education. Others say that they have minimum contacts and they do not really see the point in putting any effort to develop their relations. One respondent said, for instance, that he or she is not looking for "Polish friends", but at the same time he or she stressed that not feeling a member of the Polish community not necessarily has to mean an exclusion from it.

With respect to the Polish community, some individuals, such as Respondent 7, felt like active participants and sometimes even as organisers who are eager to present Polish culture in Wales to the locals and open up the Polish diaspora a little bit:

I feel like a participant, because I used to organise some parties or Children's Day for Poles and Polish people and I feel... that I blended a little into this community, simply because $I$ am in a committee... in Llanybydder. This is a British Committee and I am the only Polish man/woman who is there. I try to be active in those two environments and I am trying... to pull Poles into this local community, but not all of them are interested, frankly speaking (interview with Respondent 7).

The rationale behind deciding not to participate in different events that is most often given, concerns the closed and hermetic attitude of Poles who are anxious to overcome the linguistic barrier but who are afraid of being asked questions which they will not be able to answer. At the same time, parents of Polish children want them to go to Welsh schools. Hence, there are possibly two groups of Poles who try to integrate, and who are rather distant from participating in different events for many, completely different reasons.

Without a doubt, the interviewees' reactions to the question about expressing cultural legacy in Aberystwyth were full of self-criticism among the different 
respondents. The first entity that was mentioned, with regards to the expression of their own cultural legacy by the Polish diaspora, was a dynamically operating organisation called the Aberystwyth Polish Society that was established by Polish students back in 2013. At the beginning it was not very active. However, nowadays they organise, inter alia, patriotic songs contests, various patriotic events such as the Polish Independence Day on $11^{\text {th }}$ November or watch important sports events like the recent Winter Olympic Games or football matches, Polish parties, Sunday dinners, Polish masses in the Catholic Church or the promotion of Polish music:

In general sometimes I feel like more Polish here, than back in Poland (laugh). Yeah... I like it indeed... (interview Respondent 1).

To all of these events international students and locals are always invited. However, their participation is rather limited for different reasons. One should bear in mind that the majority of events that are more accessible or available to non-Polish speakers are organised by Polish students; however, sometimes it may happen that they put a lot of effort to create a 'second Poland' in Wales specifically, a sort of enclave, which is utterly unrealistic:

The younger generation, especially students, organised something because of 11 November... however some people exaggerate a little and to me personally it is... we will not create here another Poland, because Poland is in Poland. We are in Great Britain and we should respect that (interview with Respondent 2).

What is more, even if members of the Polish community have good intentions, their radical, and extreme or, perhaps, exaggerated methods might be completely counter-productive:

But this... Polish community sometimes tries to show something too negatively, even if they want to depict that well, but maybe not with these... I don't know... not necessarily with these methods, or in this particular meaning which is observed by those from outside because I have heard British people's opinions who would like to join them at some point, but everyone speaks Polish there... so... (interview with Respondent 4).

Therefore, a lack of communication in English and the omnipresent usage of Polish at those events that should have, in theory, promoted the Polish culture might be very problematic for non-Poles who simply do not speak Polish at all. Cultural, societal or historical manifestations which are created in a radical and relatively hermetic, closed way might be generally regarded as a symbol or allegory of the fact that Poland is still a closed or even xenophobic country. By replicating this image of Poland, members of the diaspora establish their own 
quasi enclave in Wales. Polish people often close up in their own immediate surroundings and are not so eager to present or promote their own culture, and when they decide to do that, they target their compatriots by using the Polish language which is not accessible to everyone:

\begin{abstract}
Hmm... I think that we do not present too much of our legacy. We close up in our group, in our small Polish community here and we do not want to promote our culture, show it to others, only among ourselves, and I have not come across this... of course there are Polish shops with Polish food (...) majority of people in these shops are Polish and in fact these kind of shops are strictly targeted at Poles who live here (...) Everything is in Polish, we should promote everything in English more, shouldn't we? (...) We close up too much. Because Polish culture is very interesting and we should promote it more (interview with Respondent 3).
\end{abstract}

One could therefore be under the wrong impression that Poles feel very well only among their fellow compatriots because of the language issue. Certainly, Poles still consider their country as poor with respect to its economy, and they do have their national complexes, mainly of an inferior nature, but, more importantly, they still have a rather negative attitude towards immigrants because of their history and the Second World War:

\begin{abstract}
I think it is because we do have a negative attitude towards foreigners because of the World Wars and the past, yeah? Poland always suffered, was robbed, and many times we were promised help, and that help was never given and we felt disappointed, we experienced a lack of trust and we still think that someone will...that...that someone don't trust us and nowadays we don't even trust each other (interview with Respondent 5).
\end{abstract}

Therefore, one could say that experiences with the Polish legacy which should have been mainly manifested by the Polish minority are rare and quite difficult to understand for people from the outside. At the same time, these members of the Polish community who have a rather sporadic or intermittent contact with Poles might completely disrupt any sense or consciousness about the way in which the Polish legacy is promoted in Wales. Apart from Polish students who came to Aberystwyth in order to get higher education qualifications, people who decided to migrate to the UK for financial purposes might have limited motivation for presenting their culture. The majority of those who belong to that group could be too tired to develop their cultural sphere:

For them it is only work-home-drink, work-home, do the shopping-drink and work... (...) they don't introduce something from themselves, they don't promote their culture in order to demonstrate it to others at all... I don't know... (interview with Respondent 8). 
Feeling tired and working hard 12 hours a day from $6 \mathrm{am}$ to $6 \mathrm{pm}$ is a fully understandable reason behind not feeling like promoting Polish culture in their free time:

\begin{abstract}
Sometimes they work from $6 \mathrm{am}$ to $6 \mathrm{pm}$ and are tired, and the only thing they have in mind is to eat and go to bed, because on the next day they have to wake up at $5 \mathrm{am}$ and go to work for 6am, so I understand that... that they don't have time, but I do think that if they would really want to [promote Polish culture], they could have done something, because for examples they have free weekends (interview with Respondent 6).
\end{abstract}

Although very often Poles do have free time to be able to show their own heritage as well as go out to people and make new friendships, they might not be interested in doing so because of their limited language proficiency or motivation. The socio-cultural impact is therefore dispersed across numerous individual attempts with very little coordination among people.

\title{
12. Conclusion
}

The Polish migration is surely the most numerous as well as the most monoethnic diasporic wave that came to Wales in 2004. The opening of the labour market by the UK government in London has significantly attracted the attention of Polish migrants and played an essential role when they were making decisions about where to migrate. Although the very history of the Polish migration is rich and extensive when one looks at migration trends in the $20^{\text {th }}$ century, it is very rarely the case that a previous diaspora played a significant role in the decision-making process regarding the very process of migration. At the same time, Poland's history of emigration and its legacy is something deeply embedded in the awareness of the vast majority of Poles who are very much conscious of their past.

Interestingly enough, Wales has been chosen by many Polish citizens who, in 2008, started to shift from large, predominantly English cities when due to various socio-political events, such as the outbreak of economic crisis, decided to change their trajectories and domicile for smaller, often rural areas. Certainly, the individual characteristics of Polish migrants made it possible to integrate quite well, which might be surprising, especially considering the total number of Poles who were noted by the 2011 Census - 18,023. The geographical as well as cultural proximity of the two states, the multi-layered mobility of the Polish migrants as well as their mostly economic motivation has contributed positively to the fluent adaptation process as well as a rather positive reception by the locals. Even though the relations among the post-1945 diaspora and the 
post-2004 one are problematic, it has been observed that the younger wave is strongly determined to promote the Polish legacy and proudly presents its society, as well as culture. Certainly, self-confidence and respect for the Welsh culture, hospitality and reception played an important role regarding the length of stay of Poles, but also their perspective on living in Wales as such (Wróbel 2015). Hence, it is important to examine further how are ideas of Welshness are engaged and negotiated by members of diasporic communities.

The study conducted in Aberystwyth shows that Polish migrants are quite critical towards themselves and see many areas for improvement when it comes to their linguistic capabilities, the way in which their culture is promoted or even what their relations with compatriots actually look like and may be perceived by others. The contribution of Polish migrants to the Aberystwyth society is quite rich. For instance, the network of students who have their own society established at the university, the existence of the Polish Delicatessen shop where Polish goods are available or the organisation of the so-called "Slavic Parties" that are accessible to everyone interested in them, contribute to the promotion of Poland's legacy as well as its heritage. The majority of newcomers who come to Aberystwyth are students and, hence, their migration patterns are rather temporary. Nevertheless, there is a quite strong representation of Polish marriages but also evidence of civil partnerships between a Polish person and other national which establish permanent patterns. Three participants out of eight interviewed for the purpose of this study had children with a non-Polish partner and in all three cases the language of (or perhaps the languages of) childrearing were similar. A Polish person addressed the child in Polish, the non-Polish partner in her or his first language, and, when together, English was used. This shows a willingness on the part of the Polish newcomers to preserve and cultivate both the homeland identity as well as the cultural legacy by passing it from one generation to the next, but also an openness for another, non-Polish heritage contribution and hybrid or multiple identity creation. The latter should be further addressed with respect to migrants' identity formation and its (re)negotiation in a Welsh context.

Furthermore, a meticulous analysis of European diaspora integration in Wales is needed. Not only could it provide us with answers regarding adaptation processes, but also it could produce a whole range of favourable and unfavourable conditions as well as factors which facilitate or impede integration. It is essential to look at the concepts of encounter and hospitality as they precede the integration phenomenon itself.

Nevertheless, I still feel there is scope to gain further insights into the reactions of the indigenous or local inhabitants to Polish and other communities. Certainly, a detailed investigation of other post-2004 EU accession countries migrants to Wales could not only provide new information about the nature of 
these migration waves, but it also would create an opportunity to juxtapose particular European diasporas with respect to socio-cultural impact or integration processes within a Welsh context.

\section{ACKNOWLEDGMENTS}

This research was funded by an ESRC Type-2 PhD Studentship (Grant number ES/I006575/1).

\section{REFERENCES}

Anderson, Bridget, Martin Ruhs, Ben Rogaly and Sarah Spencer. 2006. "Fair enough? Central and East European migrants in low-wage employment in the UK", report written for the Joseph Rowntree Foundation, published as a COMPAS Report. Available at: www.jrf.org.uk/sites/ files/jrf/1617-migrants-low-wage-employment.pdf (accessed 26 January 2016).

British Government. 2016. National Minimum Wage rates. Available at: https://www.gov.uk/ national-minimum-wage-rates (accessed 26 January 2016).

Bohata, Kirsti. 2004. Postcolonialism revisited: Writing Wales in English. Cardiff: University of Wales Press.

Burnham, Peter, Karin Gilland, Wyn Grant and Zig Layton-Henry. 2004. Research methods in politics. Houndmills: Palgrave Macmillan.

Chałasiński, Józef. 1968. Kultura i naród. Warszawa: Książka i Wiedza.

Chiswick, Barry. 1978. "The effect of Americanisation on the earnings of foreign-born men", Journal of Political Economy 86: 897-921.

Cohen, Robin. 1997. Global diasporas: An introduction. London: UCL Press.

Davies, Norman. 2001. Heart of Europe: The past in Poland's present. Oxford: Oxford University Press.

Dolowitz, David P., Steve Buckler and Fionnghuala Sweeney. 2008. Researching online. Houndmills: Palgrave Macmillan.

Drinkwater, Stephen and Michał Garapich. 2011. The TEMPO survey of recent Polish migrants in England and Wales. Cardiff: WISERD.

Drinkwater, Stephen and Michał Garapich. 2013. "Migration plans and strategies of recent Polish migrants to England and Wales: Do they have any and how do they change?", Norface Migration, Discussion Paper No. 2013-23.

Fielding, Anthony James. 1992. "Migration and social mobility: South East England as an escalator region", Regional Studies 26(1): 1-15.

Fomina, Joanna and Justyna Frelak. 2011. Światy równoległe: Wizerunek własny Polaków w Wielkiej Brytanii. Warszawa: Instytut Spraw Publicznych.

Garapich, Michał. 2008. "The migration industry and civil society: Polish immigrants in the United Kingdom before and after EU enlargement", Journal of Ethnic and Migration Studies 34(5): 735-752. 
Garapich, Michał. 2011. "Transnationalism revisited: A decade of migration between Poland and the United Kingdom", Studia Migracyjne - Przeglad Polonijny 37(1): 5-10.

Główny Urząd Statystyczny. 2015. Liczba bezrobotnych zarejestrowanych oraz stopa bezrobocia wedlug województw, podregionów i powiatów. Stan w końcu listopada 2015 r. Available at: http://stat.gov.pl/download/gfx/portalinformacyjny/pl/defaultaktualnosci/5473/2/39/1/pow11_15.xls (accessed 26 January 2016).

Guinness, Paul. 2002. Migration. Hodder \& Stoughton: London.

Janta, Hania. 2011. "Polish migrant workers in the UK hospitality industry: Profiles, work experience and methods for accessing employment", International Journal of Contemporary Hospitality Management 23(6): 803-819.

Jędrzejczak Agnieszka. 2008. „Biją naszych (gazetami)”, Przekrój 26/2008. Available at: http://wiadomosci.wp.pl/kat,37976,title,Bija-naszychgazetami,wid,10103403, wiadomosc.html (accessed 28 January 2016).

Jones, Rhys A. and Carwyn, Iorwerth Fowler. 2008. Placing the nation: Aberystwyth and the reproduction of Welsh nationalism. Politics and society in Wales: Gwasg Prifysgol Cymru.

Kłoskowska, Antonina. 2005. Kultury narodowe u korzeni. PWN: Warszawa.

Kreft, Maria B. and Felix Ritchie. 2009. The Polish migrant community in Carmarthenshire: Substance abuse and implications for the criminal justice system. Project Report. Dyfed-Powysdip, Wales. Available at: http://eprints.uwe.ac.uk/22508 (accessed 30 January 2016).

Longhi, Simonetta and Magdalena Rokicka. 2012. "European immigrants in the UK before and after the 2004 enlargement: Is there a change in immigrant self-selection?", Institute for Social and Economic Research, ESRC, No. 2012-22.

McCollom, David and Allan Findlay. 2011. "Trends in A8 migration to the UK during the recession", Population Trends 145: 73-85.

Marsh, David and Gerry Stoker. 2010. Theory and methods in political science. Houndmills: Palgrave Macmillan.

May, Tim. 2003. Social research: Issues, methods and process. Maidenhead: Open University Press.

McNabb, David E. 2010. Research methods for political science: Quantitative and qualitative approaches. London: M.E. Sharpe.

Migration Observatory. 2014. Changes to the migrant population of Wales 2001-2011. Available at: http://www.migrationobservatory.ox.ac.uk/press-releases/changes-migrantpopulation-wales-2001-2011 (accessed 26 January 2016).

Ministerstwo Pracy i Polityki Społecznej, Departament Rynku Pracy. 2008. Bezrobocie rejestrowane $w$ Polsce. Raport miesięczny - grudzień $2008 r$. Available at: https://www.mpips.gov.pl/gfx/mpips/userfiles/File/Departament\%20Rynku\%20Pracy /raporty/bezrobocie_rejestr_12.2008.pdf (accessed 26 January 2016).

Moyser, George and Wagstaffe, Margaret (eds.) 1987. Research methods for elite studies. London: Allen and Unwin.

Oates, Sarah. 2008. Introduction to media and politics. London: Sage.

Office for National Statistics. 2011a. 2011 Census: Quick statistics for England and Wales on national identity, passports held and country of birth. Available at: http://www.ons.gov.uk/ons/rel/census/2011-census/quick-statistics-for-england-andwales-on-national-identity--passports-held-and-country-of-birth/rft-qs213ew.xls (accessed 26 January 2016). 
Office for National Statistics. 2011b. Key figures for 2011 Census: Key statistics, area: Llanybydder. Available at:

www.neighbourhood.statistics.gov.uk/dissemination/LeadKeyFigures.do?a=7\&b=111 $26003 \& \mathrm{c}=\mathrm{SA} 19+7 \mathrm{RG} \& \mathrm{~d}=16 \& \mathrm{e}=62 \& \mathrm{~g}=6492379 \& \mathrm{i}=1001 \times 1003 \times 1032 \times 1004 \& \mathrm{~m}=0$ $\& \mathrm{r}=0 \& \mathrm{~s}=1454186028625 \& \mathrm{enc}=1 \& \mathrm{nsjs}=$ true $\& n s c k=$ false $\& n s s v g=$ false $\& n s w i d=1280$ (accessed 30 January 2016).

Office for National Statistics. 2011c. Polish people in the UK - Half a million Polish residents. Available at: http://www.ons.gov.uk/ons/dcp171780_229910.pdf (accessed 26 January 2016).

Office for National Statistics. 2011d. Key figures for 2011 Census: Key statistics, area: Aberystwyth. Available at:

http://www.neighbourhood.statistics.gov.uk/dissemination/LeadKeyFigures.do?a=7\& $\mathrm{b}=11119798 \& \mathrm{c}=$ Aberystwyth $\& \mathrm{~d}=16 \& \mathrm{e}=62 \& \mathrm{~g}=6491357 \& \mathrm{i}=1001 \times 1003 \times 1032 \times 1004$ $\& m=0 \& r=1 \& s=1431266205184 \&$ enc $=1$ (accessed 26 January 2016)

O'Leary, Paul. 2015. Review of Placing the nation: Aberystwyth and the reproduction of Welsh nationalism by Rhys Jones and Carwyn Fowler, National Identities 17(3): 350-351.

Okólski, Marek. 2004. "New migration movements in Central and Eastern Europe", in: Danièle Joly (ed.) International migration in the New Millenium: Global movement and settlement. Aldershot: Ashgate, 36-56.

Putnam, Robert D. 2000. Bowling Alone: The collapse and revival of American community. New York: Simon \& Schuster.

Scourfiled, Jonathan and Andrew Davies. 2005. "Children's accounts of Wales as racialized and inclusive", Ethnicities 5(1): 83-107.

Spencer, Sarah, Martin Ruhs, Bridget Anderson and Ben Rogaly. 2007. "Migrants' lives beyond the workplace: The experiences of Central and East in the UK", Joseph Rowntree Foundation. Available at: www.jrf.org.uk/publications/experiences central-and-easteuropean-migrants-uk (accessed 26 January 2016)

Sword, Keith. 1996. Identity in flux: The Polish community in Britain. London: School of Slavonic and East European Studies, University of London, London.

Thompson, Andrew, Paul Chambers and Łukasz Doleczek. 2010. “'Welcome to Llaneski': Polish migration in South West Wales", Contemporary Wales, 23(1): 1-16.

Threadgold, Terry. 2007. Constructing community in South-East Wales. Cardiff: Joseph Rowntree Foundation. Available at: http://www.cardiff.ac.uk/jomec/resources/ConstructingCommunity.pdf (accessed 31 January 2016).

Vertovec, Steven. 2009. Transnationalism. London: Routledge.

Welsh Government. 2016. Census. Available at: https://statswales.wales.gov.uk/Catalogue/Census (accessed 26 January 2016).

Wróbel, Paweł. 2015. "Problematizing hospitality: Same perception, different practice? Case study of post-2004 Polish diaspora in Wales", International Journal of Arts \& Sciences, 8(3): 221-228. 